\title{
Experimental study on the fatigue behaviour of cracked steel beams repaired with CFRP plates
}

\author{
Pierluigi Colombi*, Giulia Fava \\ Department of Architecture, Built Environment and Construction Engineering, ABC Politecnico di Milano, P.zza L. da Vinci, 32, 20133 Milan, Italy
}

\section{A R T I C L E I N F O}

\section{Article history:}

Received 6 November 2014

Received in revised form 24 March 2015

Accepted 8 April 2015

Available online 25 April 2015

\section{Keywords:}

Fatigue strengthening

Bonded CFRP strips

Cracked steel beams

Debonding

\begin{abstract}
A B S T R A C T
For the repair of damaged steel beams, Carbon Fibre Reinforced Polymers (CFRP) are effective under monotonic loads, but less information is available under fatigue loading. In this paper, fatigue tests were performed on nine CFRP reinforced cracked steel beams. The fatigue crack propagation curves showed that CFRP strips reduce the fatigue crack growth and extend the fatigue life. Experimental results also revealed the presence of a debonded area between the reinforcement and the steel substrate at the crack location. Debonding clearly has a detrimental effect on the reinforcement effectiveness. Finally, numerical and analytical studies are performed and compared to the experimental findings.
\end{abstract}

(c) 2015 Elsevier Ltd. All rights reserved.

\section{Introduction}

Steel structures and bridges may be damaged by fatigue phenomena due to traffic loadings. In this case, it is often required to study a rehabilitation activity and Carbon Fibre Reinforced Polymers (CFRPs) have been proven to be effective in the reinforcement of damaged steel beams. They are then considered as ideal products for retrofitting steel structures $[1,2]$. Besides, guidelines are available $[3,4]$ for the design of CFRP repaired steel structures.

Concerning the fatigue failure of steel beams, for reducing the crack growth rate and stopping the fatigue crack propagation, several conventional repair techniques may be taken into account, such as blunting the crack tip with a hole, bridging the cracked section by means of welding, bolting or steel plate bonding [5]. On the other hand, traditional techniques may present several disadvantages mainly due to the self-weight increase or to the fatigue sensitivity of welding and bolting. Corrosion at the edges of the reinforcing steel plates can also be a potential problem. High installation and maintenance costs also have to be considered $[1,2]$.

For all these reasons, the application of CFRP reinforcements bonded to damaged steel members by using epoxy adhesives is an emerging technique that leads to several benefits [1]. This is mainly due to the good mechanical properties of composite materials, such as high strength and stiffness, fatigue resistance, durability with a reduced self-weight. Composite materials are very flexible and their application simplifies the design of the retrofitting system. This results in easier handling and minimal maintenance costs. Moreover, the strengthening operations can be quickly realized, reducing the costs associated with the structure being out of service. The use of CFRP materials is particularly appealing for bridge applications since there is no need to close the bridge to traffic during rehabilitation. The higher CFRP cost is then mitigated by the lower installation and maintenance charges, resulting in a decrease in the global rehabilitation costs.

\footnotetext{
* Corresponding author. Tel.: +39 0223994280.

E-mail address: pierluigi.colombi@polimi.it (P. Colombi).
} 


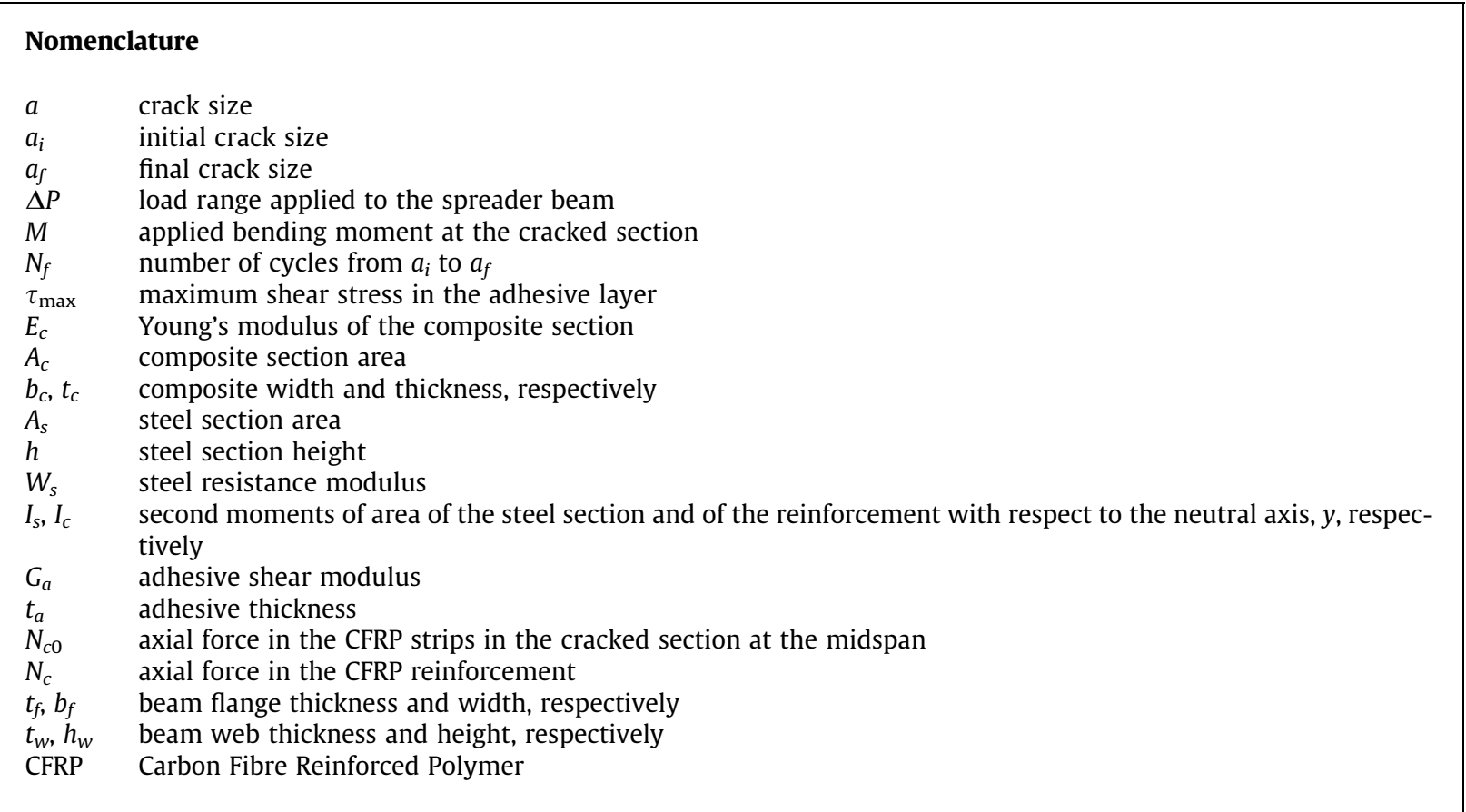

It is also relevant to consider that CFRP reinforcements do not significantly improve the elastic structural response from the global point of view. This is due to the marginal increment of the cross-sectional area and moment of inertia of the reinforced steel section. Conversely, composite materials noticeably improve the local structural response through a significant increment of the local stiffness and strength. This is quite attractive for flexural strengthening at the ultimate limit state, strengthening against local buckling, confinement of hollow steel tubes and mainly for the fatigue reinforcement.

Finally, it must be taken into account that the CFRP reinforcement is usually bonded to the steel substrate by epoxy adhesive [1,2]. Due to the high strength of the reinforcement and the steel substrate, the adhesive layer is usually the weakest point of the system. Failure modes are associated to cohesive failure in the adhesive joint, interface failure (generally at the steel-adhesive interface) and CFRP debonding. Cohesive failure can be avoided by a proper choice of the adhesive type, as an appropriate selection of the mechanical properties avoids CFRP debonding. At geometrical discontinuities (typically at the reinforcement ends), interface failure is prevented via a suitable reinforcement curtailment or mechanical anchorage. Moreover, the adhesive joint is sensitive to high temperature, water and moisture exposure. Galvanic corrosion is also a potential problem since, when the carbon fibres are in contact with the steel surface, they produce a galvanic cell. On the other hand, FRP reinforcement cannot be efficiently applied to a non-smooth surface, as in the case of riveted girders due to the high rivets density. Finally, a critical point for heritage structures is due to the fact that reversibility of the strengthening system is highly recommended, while bonded FRP materials cannot be easily removed from the steel surface.

\subsection{Problem statement}

Fatigue damage is an extremely important problem affecting steel girders in bridges. Reinforcement with CFRP materials is regarded as an efficient technique for the retrofitting of fatigue sensitive steel members. Nonetheless, quite limited information is available on the behaviour of CFRP-repaired steel members under fatigue loadings. The crack repair of fatigue damaged steel beams by using CFRP materials can be achieved in three different ways:

- by reducing the stress range around the crack tip;

- by reducing the crack opening displacement;

- by promoting crack closure.

In particular, the high reinforcement stiffness results in the reduction of the stress range around the crack tip. Besides, the use of CFRP strips bonded to the crack has an effect in bridging the crack lips, reducing the crack opening displacement and thus promoting crack closure. When pre-stressed CFRP strips are used, compressive stresses are also generated in the steel substrate and the crack closure effects are emphasized. Finally, in cracked steel elements, a severe stress/strain concentration 
is present in the crack region. A crack induced delamination then exists around the crack area and cannot be eluded by a proper reinforcement curtailment or mechanical anchorage.

\subsection{Scope of the research}

This paper discusses the results of a research program performed at the Politecnico di Milano. The fatigue behaviour of cracked I-shaped steel beams reinforced by using CFRP strips is illustrated. The use of CFRP strips bonded on the cracked steel beam, in fact, allows reducing the fatigue crack growth and extends the relevant fatigue life. A total of nine steel beams were considered and an initial crack was created by notching the tension flange and part of the web. The cracked steel beams were then reinforced by bonding CFRP strips to the bottom side of the tension flange. The effect of the reinforcement thickness was also taken into account. Fatigue tests under constant amplitude bending loads were finally performed to investigate the fatigue behaviour of the reinforced steel beams.

A debonded area at crack location was also due to the high stress/strain field. Indeed, debonding has a detrimental effect on the reinforcement and it should be considered in fatigue analysis. On the other hand, so far there has been no attempt to analyse the mutual influence between the fatigue crack propagation and the reinforcement debonding. Additionally, only few numerical models were developed to predict the fatigue behaviour of steel beams repaired with CFRP materials [1,2]. For all these reasons, this paper also focuses on the effects of a debonded zone close to the cracked section during the fatigue crack propagation. For this purpose, strain gauges were positioned on the tensile flange of some specimens, to better define how the progressive CFRP debonding may influence the crack propagation curves.

An analytical model and a three-dimensional finite element (FE) simulation were finally proposed to predict the fatigue behaviour of CFRP-repaired steel beams, taking into account the debonding between the reinforcement and the steel substrate.

\subsection{Previous studies}

Although it is well known that the use of CFRP reinforcement increases the fatigue life of steel structures [1,2], experimental campaigns in literature are mainly dedicated to the tensile members (joints). Besides, a limited amount of information is available on the effectiveness of the fatigue repair of cracked steel girders by means of CFRP strips.

Kim and Harries [6] conducted fatigue tests on steel beams initially damaged at the mid-span and reinforced by CFRP strips. They also proposed a model based on the strain-life method and cumulative damage theory to predict fatigue response of the repaired beams.

Tavakkolizadeh and Saadatmanesh [7] investigated the fatigue behaviour of $1.3 \mathrm{~m}$ long notched steel beams patched with $0.3 \mathrm{~m}$ long CFRP sheets. The fatigue performance of repaired steel beams was estimated and it was found that the CFRP reinforcement increased the fatigue lifetime of a steel beam more than three-fold and significantly decreased the crack growth rate.

In [8], the fatigue behaviour of cracked steel plates repaired by using CFRP materials was experimentally investigated. A debonded area in the crack tip region was found to considerably reduce the reinforcement efficacy.

In Nussbaumer et al. [9], fatigue tests were performed on riveted cross girders taken from a dismantled 91-year-old bridge. The use of pre-stressed CFRP reinforcements allowed stopping propagation of small cracks from rivet holes of composite steel girders. Fracture mechanics parameters and the pre-stress level required to stop fatigue crack propagation were finally estimated.

Nozaka et al. [10] investigated different combinations of two CFRP reinforcement types and five adhesive types in the fatigue behaviour of steel sections. It was reported that the better fatigue performance was obtained combining the CFRP and adhesive with the lowest moduli of elasticity.

Deng and Lee [11] analysed the fatigue behaviour of $1.2 \mathrm{~m}$ long steel beams retrofitted with CFRP patches. The crack initiation and its progressive development along the CFRP patch were monitored during cyclic loading. Based on the experimental results a stress-fatigue life $(S-N)$ curve was finally obtained.

Ghafoori and Motavalli [12] proposed and validated an analytical method based on the approach of crack surface widening energy release rate. The stress intensity factor for cracked steel I-beams was calculated. The fatigue crack growth rate, residual deflection and stiffness reduction of a cracked beam under cyclic loading were studied.

More recently, Ghafoori et al. [13] analysed the fatigue behaviour of notched steel beams reinforced by using non-prestressed and prestressed CFRP strips under cyclic loading. They considered the effects of crack propagation and FRP-to-steel debonding on the fatigue crack growth rate.

Wu et al. [14] performed an experimental campaign to analyse the fatigue behaviour of artificially notched steel beams strengthened with four different types of materials and tested under equivalent tensile stiffness. It was noticed that composite materials do not only delay crack initiation, decrease the crack growth rate and extend fatigue life, but also reduce the stiffness decay and residual deflection.

In general, all studies report that CFRP reinforcements extend the fatigue life and decrease the crack growth rate. Due to the extremely high strength of the steel substrate, the adhesive layer is the weakest point of the system and the reinforcement debonding is the dominant failure mode. On the other hand, a debonded zone close to the crack significantly reduces the effectiveness of the reinforcement technique and should be taken into account in the evaluation of the fatigue lifetime. The present paper addresses the need for further and well-documented experiments in such a field, as mentioned in [14,15]. 


\section{Experimental program}

\subsection{Test program}

Nine cracked steel beams were reinforced by using pultruded CFRP strips and tested under fatigue loading at the laboratories of the Politecnico di Milano. In repaired steel beams, the fatigue crack growth behaviour with respect to the reinforcement features is of particular interest. To this end, the presence of crack induced debonding and its effects on fatigue crack propagation are of specific concern.

I-shaped steel beams (IPE 120 according to European standard EN 10025) were selected for the experimental campaign. The beams were artificially cracked and reinforced with CFRP strips to analyse the efficacy of the repair. Specimens were machined with a notch at the midspan section through the tension flange and a portion of the web. In this way, a severe stress concentration was created in the beam and the fatigue crack growth was properly observed. Notched beams were initially subjected to fatigue loading to produce a pre-crack in the web. The specimens were then reinforced before starting the fatigue tests. Specimens are shown in Fig. 1(a), while geometric and notch details are provided in Fig. 1(b) and (c), respectively.

Fatigue tests were performed on small-scale beams, choosing a four-point bending configuration. The free length between the supports was equal to $1.0 \mathrm{~m}$ and the distance between the applied loads was of $500 \mathrm{~mm}$ (Fig. 1(a)). In particular, the damage in the beams was created by means of a $2.5 \mathrm{~mm}$ thick and $16 \mathrm{~mm}$ long blade saw cut in the flange and web and by means of an additional $1 \mathrm{~mm}$ thick and $2 \mathrm{~mm}$ long hand saw cut in the web. The supplementary $2 \mathrm{~mm}$ long saw cut was added to generate a more severe stress concentration and to promote the vertical fatigue crack propagation in the web. Specimens were finally subjected to fatigue loading in order to produce a further crack increment of 2 mm. In total, the initial crack size was then equal to $20 \mathrm{~mm}$, as shown in Fig. 1(c). After pre-cracking, specimens were reinforced and then fatigue tests started. One unreinforced beam (specimen B01) was additionally tested and used as a control specimen.

\subsection{Specimen details and preparation}

Details of the experimental program are in Table 1 , where $a_{i}$ is the initial crack size at the time of application of reinforcement, $a_{f}$ is the final crack length and $t_{c}$ is the patch thickness. Patch thicknesses of $1.4 \mathrm{~mm}$ correspond to one CFRP layer, while patch thicknesses of $2.8 \mathrm{~mm}$ correspond to two CFRP layers.

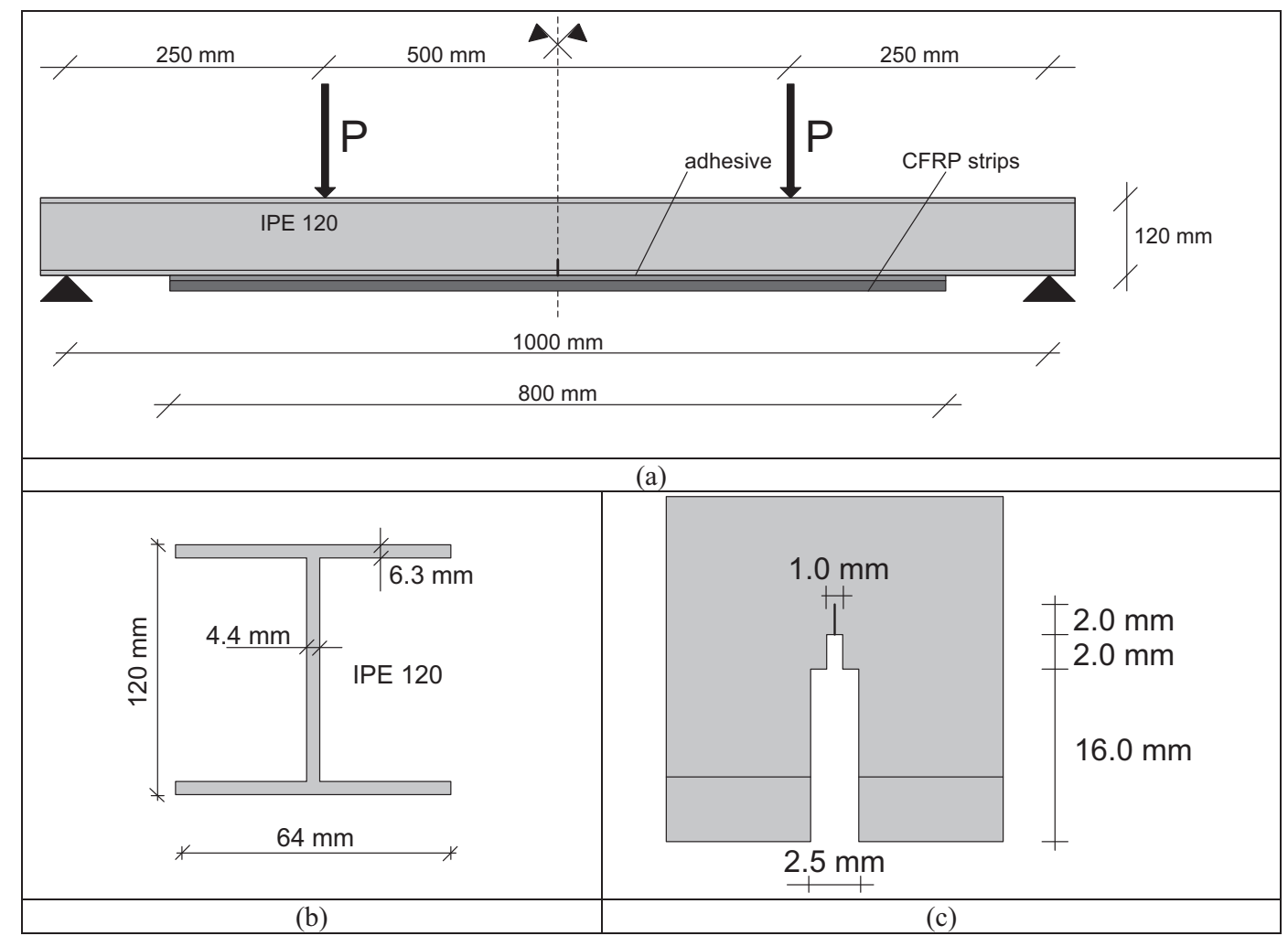

Fig. 1. Specimen geometry: (a) experimental beam geometry, (b) beam section, and (c) notch details (not to scale). 
Table 1

Test details.

\begin{tabular}{|c|c|c|c|c|c|c|c|}
\hline Specimen & $a_{i}(\mathrm{~mm})$ & $t_{c}(\mathrm{~mm})$ & $\Delta F(\mathrm{kN})$ & $a_{f}(\mathrm{~mm})$ & $N_{f}(-)$ & Normalized initial stiffness & Normalized final stiffness \\
\hline B01 & 20 & 1 & $6-15(10 \mathrm{~Hz})$ & 60 & 233,500 & $100 \%$ & $84 \%$ \\
\hline B02 & 20 & 1.4 & $6-15(10 \mathrm{~Hz})$ & 20 & 280,000 & $136 \%$ & $134 \%$ \\
\hline $\mathrm{B} 03^{\mathrm{a}}$ & 20 & 1.4 & $28-70(3 \mathrm{~Hz})$ & 60 & 19,700 & $136 \%$ & $119 \%$ \\
\hline B04 & 20 & 1.4 & $28-70(3 \mathrm{~Hz})$ & 60.9 & 24,000 & $131 \%$ & $113 \%$ \\
\hline B05 & 20 & 2.8 & $28-70(3 \mathrm{~Hz})$ & 60.4 & 183,000 & $146 \%$ & $134 \%$ \\
\hline B06 & 20 & 2.8 & $28-70(3 \mathrm{~Hz})$ & 60.9 & 114,000 & $142 \%$ & $133 \%$ \\
\hline B07 & 20 & 2.8 & $28-70(3 \mathrm{~Hz})$ & 60.4 & 228,000 & $142 \%$ & $133 \%$ \\
\hline B08 & 20 & 2.8 & $28-70(3 \mathrm{~Hz})$ & 60.2 & 180,000 & $142 \%$ & $133 \%$ \\
\hline В09 & 20 & 2.8 & $28-70(3 \mathrm{~Hz})$ & 35 & 185,000 & 1 & 1 \\
\hline
\end{tabular}

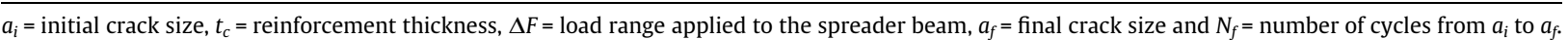

a Retested.

\subsubsection{Materials}

Specimens were prepared using a steel type S275J0, according to European standard EN 10025. The mechanical properties of the steel plates were determined through tensile coupon tests. The mean yielding stress and tensile strength were of 330 and $444 \mathrm{MPa}$, respectively. The steel Young's modulus was assumed equal to $208 \mathrm{GPa}$.

The pultruded reinforcements were obtained using CFRP strips (Sika CarboDur ${ }^{\circledR}$ M614) with a thickness of 1.4 mm, a width of $60 \mathrm{~mm}$ and a length of $800 \mathrm{~mm}$. It is a high resistance CFRP reinforcing system for concrete, masonry, timber and steel structures. In particular, its Young's modulus is comparable to the steel one. The nominal values of the Young's modulus and tensile strength were greater than $200 \mathrm{GPa}$ and $2800 \mathrm{MPa}$, respectively. The reinforcement Young's modulus was assumed equal to $195 \mathrm{GPa}$.

The pultruded CFRP strips were bonded to the steel plates using a thixotropic epoxy resin (Sikadur ${ }^{\circledR} 30$ ). It is a two-component, high modulus, high strength structural epoxy paste bonding adhesive. The mixing ratio of the epoxy was three parts of component A (resin) to one part of component B (hardener) by volume/weight. The epoxy had a pot life of 70 min and was cured at room temperature. The adhesive Young's modulus and tensile strength were greater than 4500 and 28.4 MPa, respectively.

For specimens reinforced with two layers of pultruded CFRP strips, a less viscous epoxy (Sikadur ${ }^{\circledR} 330$ ) was used to bond the outer CFRP strip to the inner one. The mixing ratio in this case was four parts of component A (resin) to one part of component B (hardener) by weight. The epoxy had a pot life of $30 \mathrm{~min}$ and was cured at room temperature. The nominal values of the Young's modulus and tensile strength were greater than 3800 and $30 \mathrm{MPa}$, respectively.

\subsubsection{Specimen preparation}

Steel beams were initially machined with an $18 \mathrm{~mm}$ long and $2.5 \mathrm{~mm}$ wide notch. Specimens were then subjected to fatigue loads to create an initial pre-crack with length of approximately $20 \mathrm{~mm}$. The pre-crack represented an initial damage condition and was performed to investigate the fatigue crack propagation in the reinforced beam. Next, notched specimens were reinforced according to the following procedure (see Fig. 2).

Before bonding the CFRP reinforcement to the cracked steel section, the bottom side of the tension flange was accurately grid blasted by using an abrasive disc in order to remove the rust and to create a rough surface, as shown in Fig. 2 a. Then a xylene-based solvent was used to remove dust and obtain a clean and chemically active surface to ensure mechanical interlocking. For the CFRP reinforcement, very fine sandpaper (grit P240) was used to increase the surface roughness and hence improve the bond strength. In order to avoid any possible contamination, immediately after the surface preparation, 60 mm wide CFRP strips were cut to a length of $800 \mathrm{~mm}$ by using a saw cut and were bonded to the steel substrate. To simulate an on-site reinforcement application, no adhesive promoter (e.g. primer) was used and no spacers were applied to control the adhesive thickness.

The two components of the epoxy adhesive were dosed according to the manufacturer's instructions and mixed until a homogeneous light grey paste was obtained (Fig. 2b). The adhesive (Sikadur ${ }^{\circledR} 30$ ) was then evenly distributed on the composite at the bottom side of the tension flange. The CFRP strips were pressed on the steel substrate to avoid air bubbles, and the adhesive in excess was removed (Fig. 2c). An average adhesive thickness equal to 2.5 mm was obtained.

In the case of specimens reinforced with two layers of pultruded CFRP strips, the adhesive (Sikadur ${ }^{\circledR} 330$ ) was distributed on the composite material, and the outer strips were pressed on the previously applied ones. Finally, the specimens were cleaned and subjected to uniform pressure by applying dead weights on the CFRP surface. After 2 days, the dead weights were removed, and the bond line visually inspected. Reinforced specimens are shown in Fig. 2(d).

\subsection{Measuring and recording equipment}

All beams were subjected to four-point flexural loading over a simply supported span of $1000 \mathrm{~mm}$ (see Fig. 1). A special test rig was designed to perform the experimental tests (see Fig. 3) by using a hydraulic testing machine with a loading 


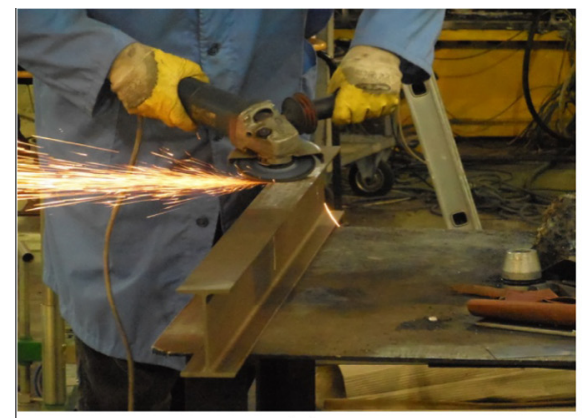

(a)

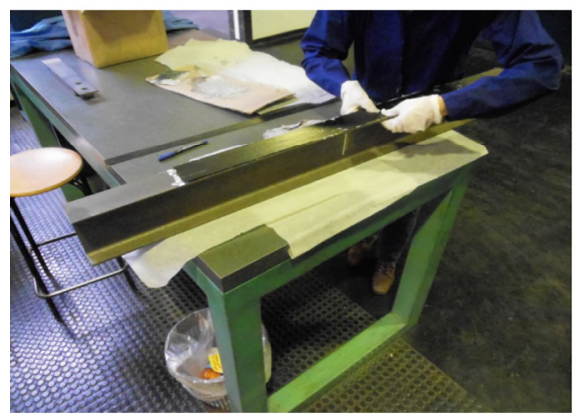

(c)

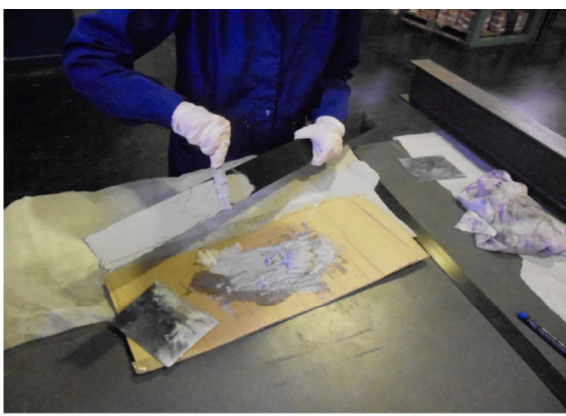

(b)

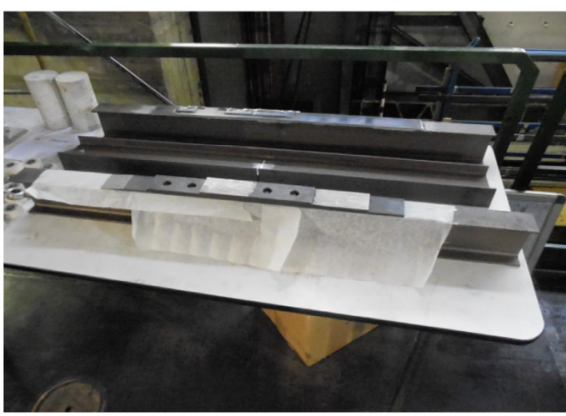

(d)

Fig. 2. Specimen preparation: (a) surface preparation, (b) adhesive distribution, (c) CFRP strips are pressed, and (d) reinforced specimen.

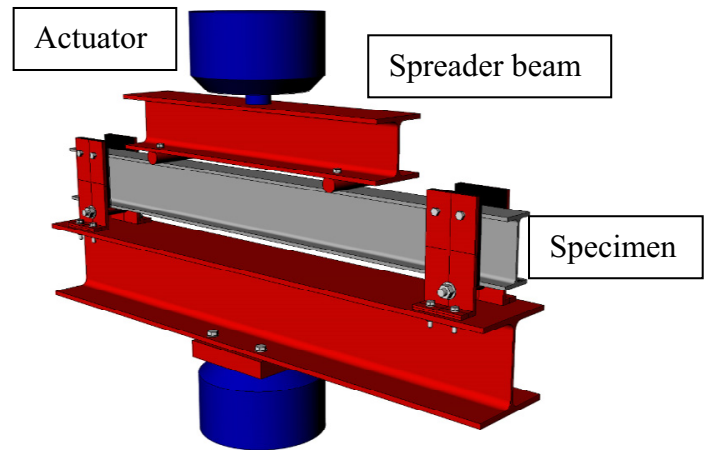

Fig. 3. Test setup.

capacity of $250 \mathrm{kN}$. A spreader beam was also used to distribute the load to the beam, as shown in Fig. 3. Details of the loading range and frequency are reported in Table 1.

During the execution of fatigue tests, it was essential to capture the crack growth development with respect to the fatigue cycles. As shown in Fig. 4, after positioning a piece of graph paper close to the ligament on the beam web, the crack growth was recorded at intervals from 500 to 10,000 cycles, depending on the crack front speed, by using a travelling microscope with a magnifying power up to $220 \times$.

For selected specimens B04, B06, B07 and B09, the CFRP strips were instrumented with 8 strain gauges close to midspan, aiming to investigate the tensile strain distributions along the CFRP strip and to monitor the progressive debonding propagation of the reinforcement in the vicinity of the notch (Fig. 5).

\subsection{Fatigue tests}

The fatigue tests were performed under constant amplitude cycling loads with different amplitude and frequency, as showed in Table 1 . Note that the applied load, $F$, listed in Table 1 refers to the one applied by the actuator of the testing machine to the spreader beam. The applied loads $P=F / 2$ (see Fig. 1 ) are then one half of the one reported in Table 1 . Specimens B01 (unreinforced) and B02 were tested at a load range of 6-15 kN and a frequency of $10 \mathrm{~Hz}$. The selected maximum fatigue loading, $P_{\max }=15 \mathrm{kN}$, was equal to $50 \%$ of the calculated yield load for the un-reinforced beam, based on the 


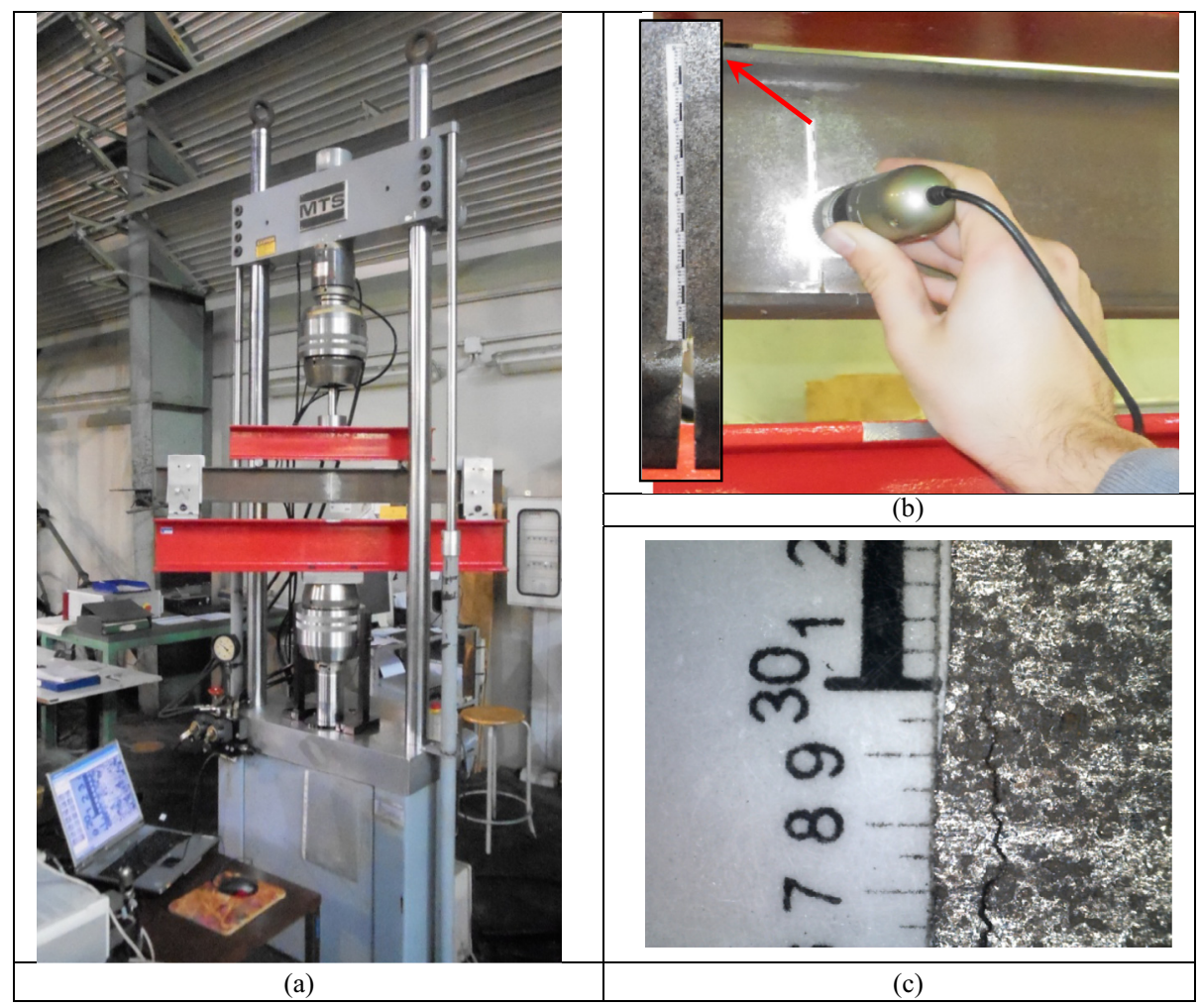

Fig. 4. Experimental test and measuring system: (a) four-point bending test, (b) travelling microscope, and (c) crack measurement.

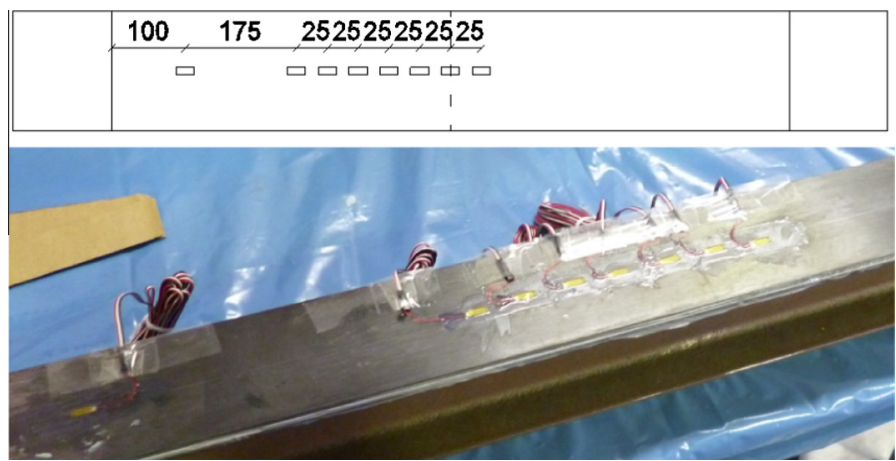

Fig. 5. Strain gauges layout and positioning.

midspan notched section. The minimum load, $P_{\min }=6 \mathrm{kN}$, was equal to $20 \%$ of the yield loading, resulting in a load ratio of 0.4 . The adopted loading ratio $R=0.4$ was chosen to reproduce a severe fatigue crack propagation scenario. In fact, at such a loading ratio, the retardation effects were minimized and the fatigue crack propagation was then faster. The other beams (from beam B03 to beam B09) were tested at an increased load range $(28-70 \mathrm{kN})$ to more suitably investigate the fatigue crack growth in the repaired specimens. In this case, no reference (unreinforced) specimen was tested since the relevant maximum load was too large and it would produce beam static failure. Besides, as the aim of the work is to analyse the stable fatigue crack growth in reinforced specimens, fatigue tests were stopped when the crack propagation reached the final crack size, $a_{f}$, listed in Table 1 .

\section{Analytical modelling}

The stress evaluation in the CFRP reinforcement and in the adhesive layer is fundamental to investigate the reinforced beam behaviour and to predict the failure load of the adhesive layer. Different models were proposed in literature for these purposes [1,2]. These models can be classified in two main groups. The models of the first group do not take into account the 
slippage between the adherents, while in the models of the second group the relative displacement between the steel and the CFRP at the interface is considered. Note that if the slippage between the adherents is not taken into consideration, stress concentrations around physical discontinuities (as reinforcement ends or intermediate crack) cannot be captured. Additionally, some models of the second group take into account the non-linear behaviour of the interface; that is, at the interface a non-linear bond-slip relationship is proposed. In case of non-linear interface behaviour, an analytical solution is available just for simple reinforcing schemes such as single and double lap joints, but there is no analytical solution for reinforced beams. On the other hand, if linear interface behaviour can be adopted up to failure, several analytical solutions are proposed in literature [1,2]. They are summarized in the following Section in order to better understand and clarify the experimental findings.

\subsection{Adhesion analysis with linear interface behaviour}

Under the hypothesis that linear interface behaviour is maintained up to failure, an analytical model for the stress evaluation in the CFRP reinforcement and in the adhesive layer is proposed. The basic assumptions are as follows:

1. elastic stress-strain relationship for steel and CFRP and linear interface behaviour up to failure;

2. plane sections remain plane during bending;

3. stresses in the adhesive layer do not change with thickness; that is, the adhesive layer is thin;

4. the bending stiffness of the strengthened beam is much greater than the stiffness of CFRP strips.

Based on the last assumption, the bending moment in the CFRP strips and the normal stresses in the adhesive layer can be neglected when the tensile stress in the CFRP reinforcement and the shear stress in the adhesive joint are evaluated. With reference to Fig. 6, the maximum shear stress in the adhesive layer is computed as:

$$
\tau_{\max }=\frac{\lambda}{b_{c}}\left(N_{c 0}-\frac{M}{f_{2} E_{s} W_{s}}\right)
$$

where $M$ is the applied bending moment and:

$$
\begin{aligned}
\lambda^{2} & =\frac{G_{a} b_{c}}{t_{a}}\left(\frac{1}{E_{c} A_{c}}+\frac{1}{E_{s} A_{s}}+\frac{h}{2 E_{s} W_{s}}\right) \\
f_{2} & =\lambda^{2} \frac{t_{a}}{G_{a} b_{c}}
\end{aligned}
$$

and $E_{c}, A_{c}$ and $b_{c}$ are the composite section Young's modulus, section area and width, respectively, $E_{s}, A_{s}$ and $h$ are the steel section Young's modulus, section area and height while $W_{s}$ is the steel resistance modulus. $G_{a}$ and $t_{a}$ are the adhesive shear modulus and thickness, respectively.

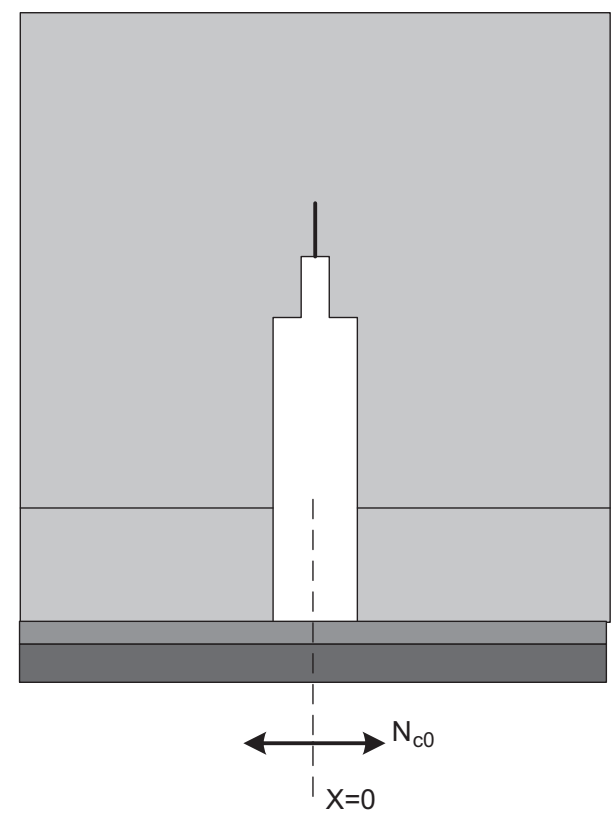

Fig. 6. Adhesion analysis at the midspan: initial condition and reference axis. 
In Eq. (1), $N_{c 0}$ is the CFRP strip axial force in the cracked section at the midspan. It can be easily determined by means of a sectional analysis of the cracked section as showed in the next Section.

\subsection{Sectional analysis of the cracked section}

The sectional analysis of the cracked section allows the estimation of the tensile force in the CFRP reinforcement at the beam cracked section. The basic assumptions are:

1. elastic stress-strain relationship for steel and CFRP;

2. plane sections remain plane during bending;

3. no slippage between steel and CFRP, i.e. perfect composite section.

The cracked steel section and the CFRP reinforcement are analysed as a composite element and the plain section assumptions are employed for the evaluation of strains and stresses. The process is summarized in Fig. 7.

In particular, the axial (tensile) stress in the CFRP reinforcement will be computed and compared to the ones obtained from the strain gauges readings. At first, for estimating the stresses in the composite layer, the neutral axis position, $y$, of the centroid, $G$, is calculated at the cracked section (see Fig. 7 for the nomenclature):

$$
y=\frac{b_{f} t_{f}\left(h_{w}+1.5 t_{f}\right)+0.5\left[\left(h_{w}+t_{f}\right)^{2}-a^{2}\right] t_{w}-m b_{c} t_{c}\left(0.5 t_{c}+t_{a}\right)}{b_{f} t_{f}+\left(h_{w}+t_{f}-a\right) t_{w}+E_{c} b_{c} t_{c}}
$$

Next, the second moment of area, $I$, of the composite section is computed as $I=I_{S}+I_{c}$, where:

$$
\begin{aligned}
& I_{s}=\frac{b_{f} t_{f}^{3}}{12}+b_{f} t_{f}\left(h_{w}+1.5 t_{f}-y\right)^{2}+\frac{t_{w}}{12}\left(h_{w}+t_{f}-a\right)^{3}+\left[y-\frac{1}{2}\left(h_{w}+t_{f}-a\right)\right]^{2}\left(h_{w}+t_{f}-a\right) t_{w} \\
& I_{c}=m\left[\frac{b_{c} t_{c}^{3}}{12}+b_{c} t_{c}\left(y+0.5 t_{c}+t_{a}\right)\right]
\end{aligned}
$$

In Eq. (4), $I_{s}$ and $I_{c}$ are the second moments of area of the steel section and of the reinforcement with respect to the neutral axis, respectively, while $m=E_{c} / E_{s}$ is the Young's modulus ratio. Finally, the axial force, $N_{c}$, in the CFRP reinforcement is evaluated as:

$$
N_{c}=A_{c}\left[m \frac{M}{I}\left(y+0.5 t_{c}+t_{a}\right)\right]
$$

The axial force in the CFRP reinforcement produces a compressive stress field in the steel beam, which, from one hand, radically reduces the stress intensity factor in the cracked section [12] and from the other hand promotes crack closure by decreasing the crack opening displacement. Both these effects result in a significant reduction of the fatigue crack growth rate, enhancing then the fatigue lifetime.

\section{Numerical modelling}

In addition to the experimental tests and to the adhesion analysis, a finite element simulation was performed to investigate the reinforcement effectiveness on the fatigue performance of cracked steel beams.

\subsection{Geometry, mesh and boundary conditions}

A three-dimensional finite element model made of 2D shell elements was used to simulate the reinforced steel beam. The use of 2D shell elements allowed reducing the computational effort. The commercial finite element code ABAQUS was employed. The reinforced steel beam shown in Fig. 1 was numerically modelled. The geometric model contained three parts: the steel plate, the adhesive layer and the CFRP reinforcement, see Fig. 8(a).

Four-node shell elements (S4R) were employed and the mesh was assembled as follows: 35,702 nodes and 34,733 elements for the steel plate; 5805 nodes and 5512 elements for both the adhesive and the composite reinforcement. As shown in Fig. 8(b), a special mesh with quarter point elements was used to detect the strain singularity at the crack tip and, eventually, to calculate the stress intensity factor (SIF).

The finite-element analyses were performed by applying on the steel upper flange an increasing stress, corresponding to the maximum flexural fatigue loading.

\subsection{Material model and interface behaviour}

Both the steel and the CFRP reinforcement were modelled as isotropic materials. Elastic-plastic behaviour was assumed for the steel while the CFRP was considered as a linear elastic material. The steel plate had Young's modulus and Poisson 

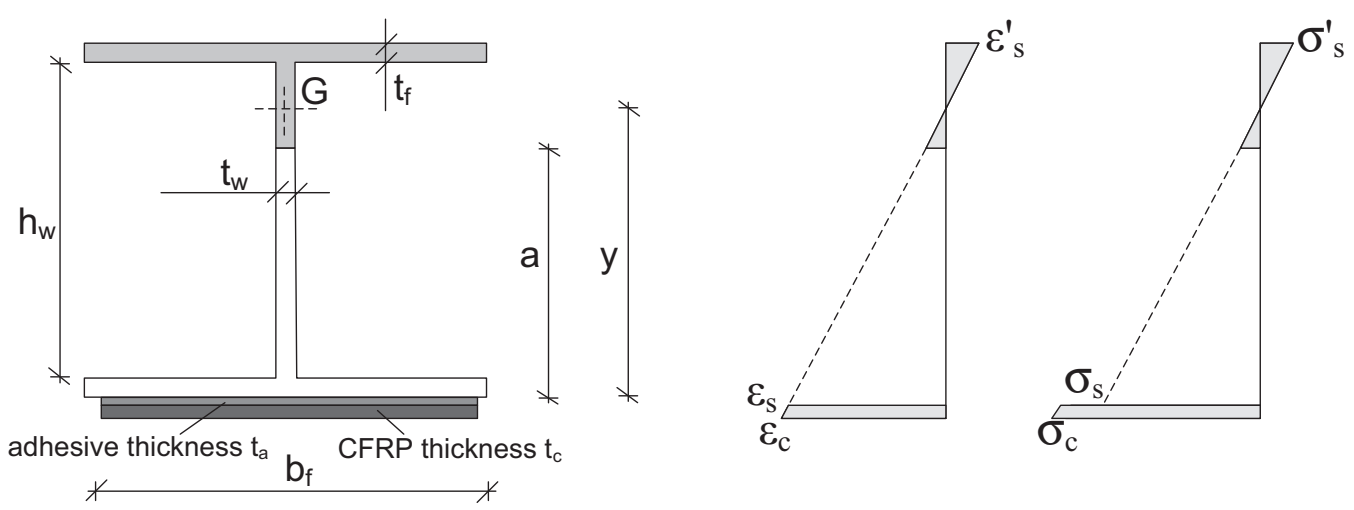

Fig. 7. Cracked sectional analysis at the midspan: strains and stresses in the steel beam and CFRP strips.

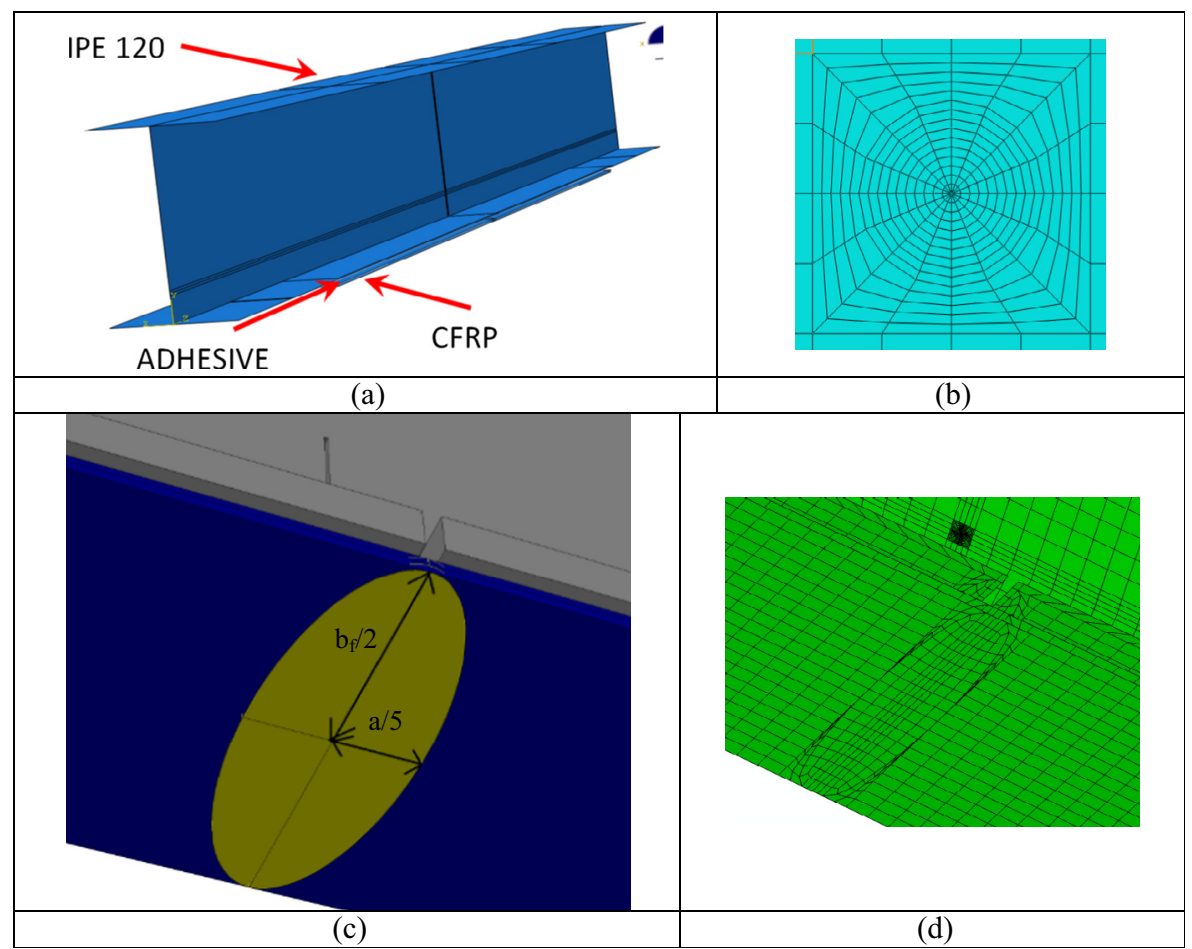

Fig. 8. Finite element model: (a) assembly of the reinforced beam, (b) detail of the fine mesh at the crack tip, (c) debonded area close to the crack region, and (d) finite element mesh at the debonded area.

ratio equal to $208 \mathrm{GPa}$ and 0.3 , respectively. The CFRP reinforcement had Young's modulus and Poisson ratio of $210 \mathrm{GPa}$ and 0.3 , respectively. The adhesive had Young's modulus and Poisson ratio of $4.5 \mathrm{GPa}$ and 0.3 , respectively.

Surface-to-surface tie constraints were applied to model the connection between the beam bottom flange and the CFRP reinforcement. Such a constraint type prevented the relative displacement between the surfaces. In this way, the material properties of the adhesive layer were not included in the model. Such a simplified assumption was adopted because the slippage between the adherents was not considered; that is, perfect bond was postulated.

The presence of a steel crack clearly produced a stress concentration in the adhesive layer close to the middle section of the steel beam. If the stresses in the adhesive layer were too large, the stress concentration would yield to debonding at the steel-adhesive interface (intermediate debonding). In order to model this phenomenon, a debonded region was eventually introduced in the finite element model. The shape of the debonded region was assumed to be elliptical and depended on the crack size, $a$. As shown in Fig. 8(c), the major axis of the ellipse was set to be equal to the width of the tension flange, while the minor axis was supposed to be equal to $2 a / 5$. In such a way, the size of the debonded region increased with the crack size, taking implicitly into account the propagation of the interface crack during the fatigue tests. 


\section{Results}

\subsection{Experimental results}

In the following, the experimental results are presented in terms of fatigue behaviour, fatigue crack growth curves of the reinforced specimens and CFRP strain distribution. A detailed discussion of the experimental findings is provided in Section 6.

\subsubsection{Fatigue behaviour}

The number of cycles to achieve the prescribed final crack length is reported in Table 1 . The last two columns of Table 1 describe the recorded specimen stiffness at the initial and final crack size, respectively. The specimen stiffness is defined as the ratio between the applied load $P$ (measured by the load cell of the testing machine) and the crosshead displacement $\Delta$ (measured by the displacement transducer of the stroke). The stiffness was normalized with reference to the initial stiffness of the unreinforced specimen.

At the final crack size of $60 \mathrm{~mm}$, after about 230,000 duty cycles, the unreinforced specimen B01 showed a stiffness reduction to $84 \%$. On the other hand, the fatigue test of the reinforced specimen B02 was stopped at 280,000 duty cycles, since no crack propagation was observed and therefore no beam stiffness variation was recorded. This means that, at about 230,000 duty cycles, the unrepaired specimen B01 presented significant fatigue damage while no crack propagation was noticed in the reinforced beam B02.

Specimens B02 was then retested as specimen B03 increasing the load range to $28-70 \mathrm{kN}$. The same load range was also used for specimens B04-B09. In the beams reinforced with one CFRP layer (specimens B03 and B04), some degree of debonding was observed after performing the fatigue cycles. In fact, visual inspection of the adhesive bond-line by using a digital microscope clearly revealed the presence of a fatigue crack along the bond-line.

\subsubsection{Fatigue crack growth curves}

In Fig. 9(a), the fatigue crack growth curves are plotted.

The composite reinforcement bridges the stress in the cracked section, reduces the crack opening displacement and promotes crack closure, leading to a fatigue life extension. Significantly slower crack propagation rate was observed for the double reinforcement compared to the single one. This results from the fact that, when two composite layers are bonded to the tensile flange, a greater crack bridging effect is reached.

A detailed inspection of the fatigue crack growth curves for beams reinforced with two CFRP layers revealed that:

- the fatigue crack growth can be significantly improved by increasing the number of reinforcement layers. In particular, the fatigue life is nine times greater for two CFRP layers compared to the single one (see Fig. 9(a));

- at the beginning of the tests, the crack growth rate is quite large, resulting in a faster fatigue crack propagation. This is clearly shown in Fig. 9(b), which reports a detail of the fatigue crack curves up to ten thousand duty cycles;

- an even faster fatigue crack growth rate was observed for a crack size ranging from approximately $40 \mathrm{~mm}$ to the final crack size.

In Fig. 9, it is finally evidenced that the fatigue crack growth in CFRP reinforced beams is a quite complex phenomenon resulting from the interaction of the fatigue performance of the steel beam and the interface behaviour.

\subsubsection{CFRP strain distribution}

Fig. 10 shows the strain distributions measured along the CFRP strip by using strain gauges for increasing crack lengths.

Specimens B04, B06, B07 and B09 were considered. It may be noticed that the strain distributions are symmetric with respect to the midspan, but the strains tend to spread as far as the crack size increases, due to the progressive debonding in the adhesive layer. In particular, the strain profiles for specimen B04 indicated the presence of a debonded area close to the cracked section and were useful to explain the shape of the fatigue crack propagation curves. The strain profile, in fact, exhibited a plateau up to approximately $50 \mathrm{~mm}$ from the midspan, indicating CFRP reinforcement debonding in this region. This phenomenon is less evident but still present in specimens B06, B07 and B09 that were reinforced with two CFRP strips.

\subsection{Analytical and numerical results}

In this section, the analytical and numerical results are presented in terms of the CFRP strip tensile force in the cracked section. A detailed discussion of the analytical and numerical findings is provided in Section 6. The CFRP strip axial forces obtained from the adhesion analysis and from the FEM simulation were compared to the results of the experimental tests. The evaluation of the CFRP strip tensile force is very important to understand the fatigue behaviour of the reinforced steel beam. The tensile force in the CFRP strips, actually, indicates the capacity of the reinforcement to bridge the crack and to reduce the fatigue crack growth. In fact, the higher the tensile force in the CFRP strips, the lower the stress intensity factor 


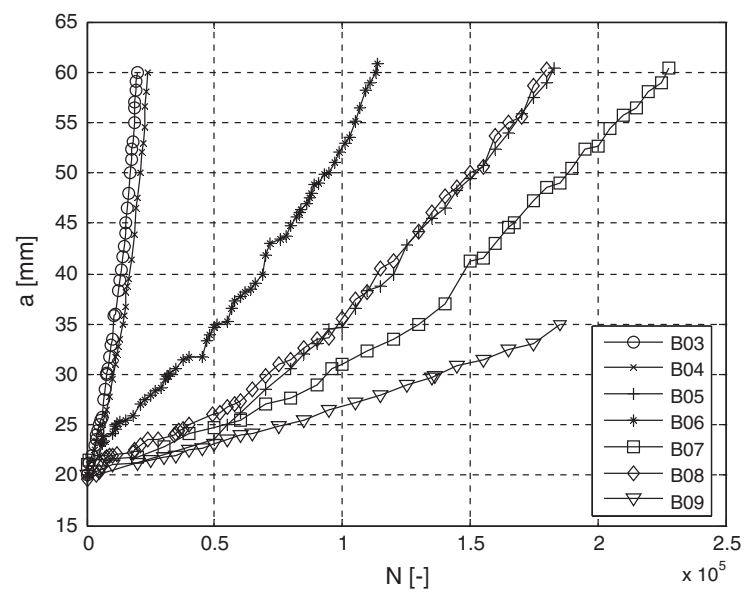

(a)

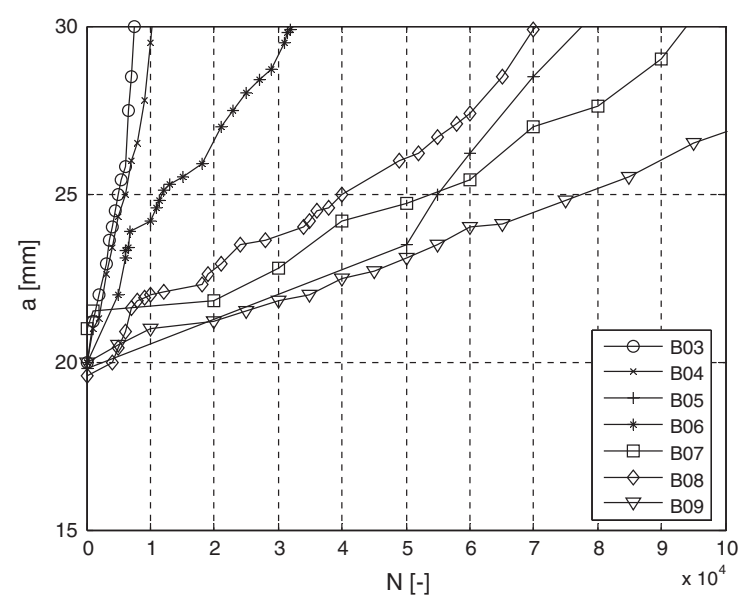

(b)

Fig. 9. Fatigue crack growth results: (a) crack propagation curves, and (b) detail for short crack.

in the steel beam and then the slower the fatigue crack propagation. Fig. 11 illustrates the results for specimen B04, which was reinforced with a single CFRP layer.

In Fig. 11, analytical outcomes from the sectional analysis of the cracked section are reported as a continuous line, while the experimental results are superimposed as circles. The analytical results are computed from the sectional analysis of the cracked section outlined in Section 3.2. The experimental results are obtained from the strain readings (see Fig. 10) in the following way. At first, the microstrain, $\varepsilon_{0}$, at $x=0$, is evaluated from Fig. 10 and the tensile force in the CFRP strip is calculated as $N_{c}=\varepsilon_{0} \cdot E_{c} \cdot A_{c}$, where $E_{c}$ is the Young's modulus of the reinforcement and $A_{c}$ is the composite section area.

Fig. 12 illustrates the results for specimens B06, B07 and B09, which were reinforced with two CFRP layers.

In Fig. 12, analytical outcomes from the sectional analysis (see Section 3.2) of the cracked section are reported as a continuous line, while the experimental results are superimposed as circles. The experimental results are obtained from the strain gauges readings (see Fig. 10) as explained above.

\section{Discussion}

In this section, the experimental findings and the predicted behaviour of the beams resulting from the proposed numerical and analytical models are discussed.

Experimental results show the effectiveness of the repair of cracked steel beams by using CFRP strips, leading to a significant increment of the fatigue lifetime. Comparison of the fatigue behaviour of un-repaired and repaired steel beams is possible only for specimens B01 and B02, which were tested at the same load level. Specimen B01 showed a fast fatigue crack growth (see Table 1) and the final crack size, $a_{f}=60 \mathrm{~mm}$, was reached at 233,500 duty cycles. The application of a single reinforcement layer (specimen B02) produced no fatigue damage after 280,000 duty cycles. This means that, at about 230,000 


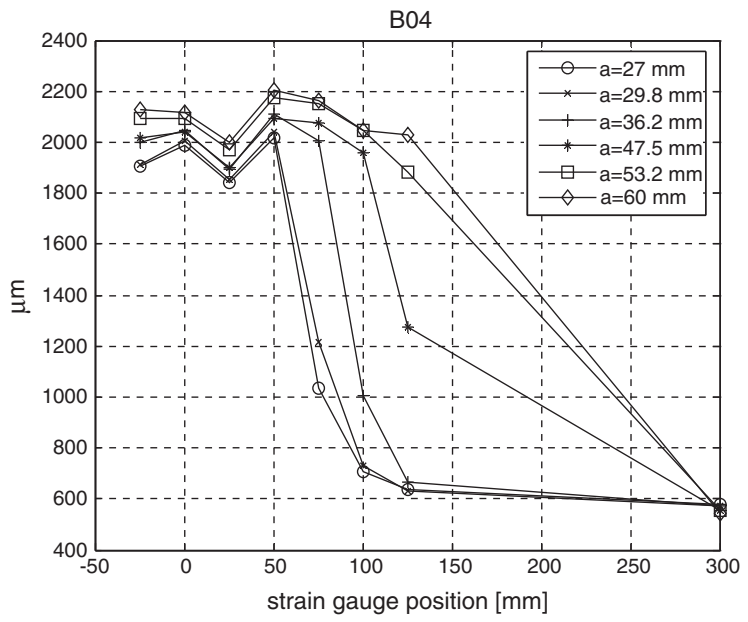

(a)

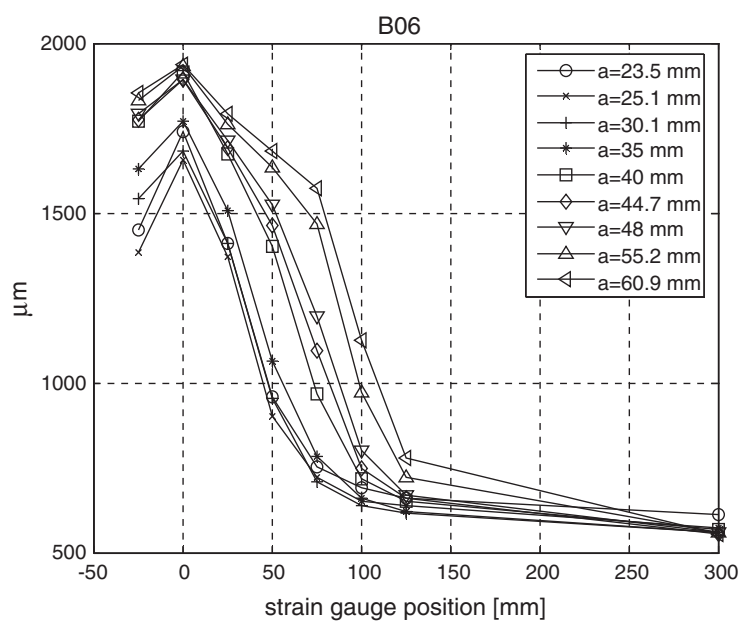

(b)

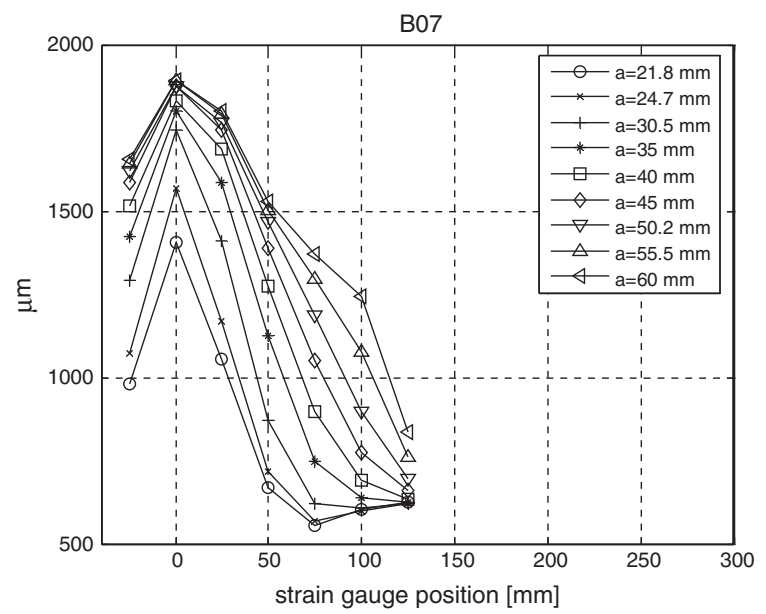

(c)

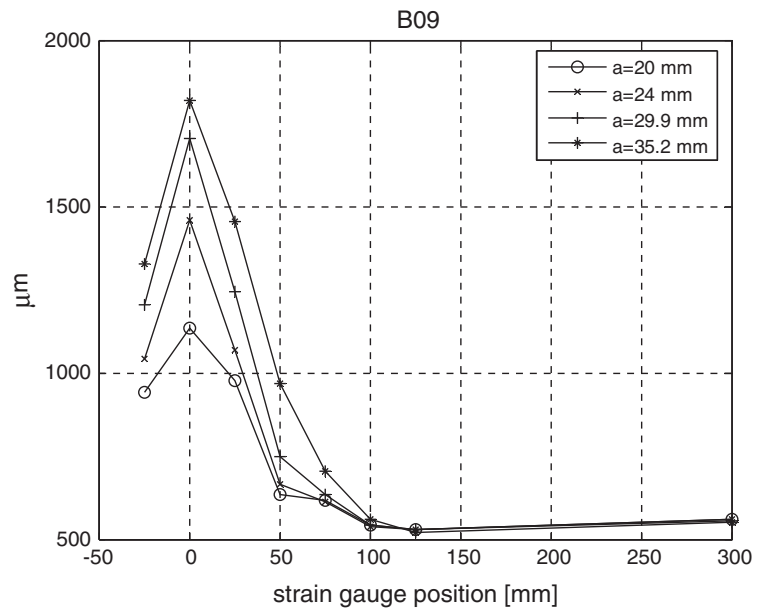

(d)

Fig. 10. Strain gauge measurement: (a) specimen B04 (1 layer), (b) specimen B06 (2 layers), (c) specimen B07 (2 layers), and (d) specimen B09 (2 layers).

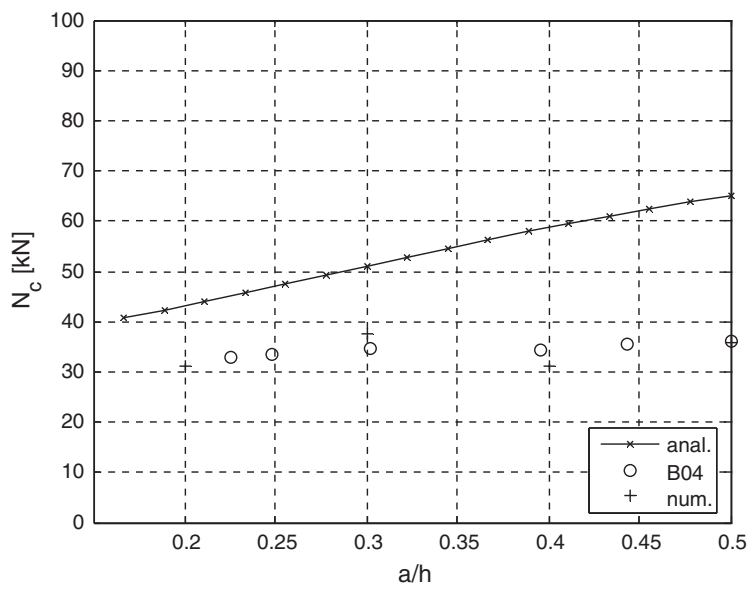

Fig. 11. Tensile force in the composite strip at the cracked section: experimental, analytical and numerical results for single layer reinforcement (specimen B04). 


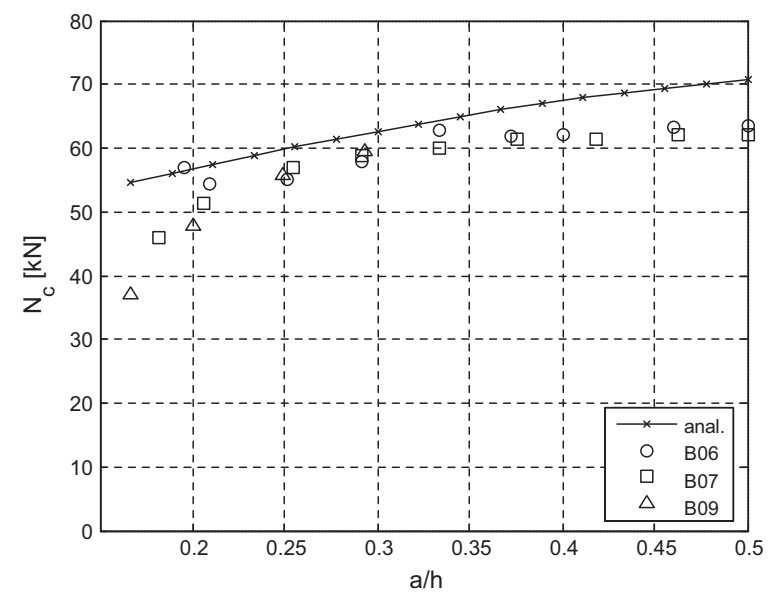

Fig. 12. Tensile force in the composite strip at the cracked section: experimental and analytical results for double layers reinforcement (specimen B06, B09 and B07).

duty cycles, the unrepaired specimen B01 presented significant fatigue damage while no crack propagation was observed in the reinforced beam B02. This is a strong evidence of the effectiveness of fatigue repair of cracked steel beams by using CFRP strips, as clearly showed in literature [6-15].

Fast fatigue crack growth was noticed in specimens B03 and B04 (one reinforcement layer) and debonding was clearly observed from the strain gauge measurements. In that case, a higher stress range was selected to properly investigate the fatigue behaviour of beams strengthened with two reinforcement layers and, as a result, fast crack propagation was found in specimens B03 and B04 with a single reinforcement layer (see Fig. 9).

The debonding influence on the CFRP strip tensile force is clearly illustrated in Fig. 11. Besides, the sectional analysis of the cracked section (see Section 3.2) evidently failed in the prediction of the CFRP tensile force since the debonding effect was not taken into account. On the other hand, in the finite element model (see Section 4), the introduction of a debonding at the cracked section provided a correct estimation of the CFRP tensile force. In beam B04, debonding was in fact identified closed to the midsection as a longitudinal strain plateau of $2000-2200 \mu \mathrm{m}$ was measured by the strain gauges in the CFRP, see Fig. 10(a). Beyond the debonded zone, the stress rearranged back into the steel beam and the corresponding CFRP stresses and strains reduced. Such a strain level in the debonded region is also in agreement with the experimental results in [10]. Additionally, Eq. (1) can be used to estimate the maximum allowable tensile force in order to prevent debonding. To this end, the allowable adhesive shear stress of $20 \mathrm{MPa}$ can be roughly estimated according to [10] [14]. Inserting this value in Eq. (1), for an external bending moment of $8.75 \mathrm{kN} \mathrm{m}$, an admissible CFRP tensile force equal to $34.5 \mathrm{kN}$ is achieved. This analytical value is in agreement with the CFRP tensile force experimentally obtained and reported in Fig. 11.

In Fig. 12, for specimens B05-B09 (two reinforcement layers), the results of the sectional analysis in terms of the CFRP axial force in the cracked section with respect to the crack length (see Section 3.2) were compared to the experimental findings. Again, the sectional analysis failed in the prediction of the tensile force in the CFRP since debonding is present. When $a / h<0.2$, the experimental axial force at the midsection was significantly lower than the analytical predicted behaviour and the sectional analysis of the cracked section failed in the prediction of the experimental trend. This means that for small crack size in the steel beam, the stress redistribution between the steel flange and the CFRP is reduced and lower axial force is carried by the reinforcement. In fact, the steel beam stiffness and the reinforcement stiffness control the stress redistribution. For small crack size, the beam stiffness is quite large compared to the reinforcement one and the stress redistribution occurs only in the first composite layer. As the crack length increases, the beam stiffness decreases and, as a result, both the reinforcement layers are involved in the stress redistribution. This has a strong influence on the fatigue crack growth as clearly evidenced in Fig. 9(b). Fig. 12 exhibits also a progressive marginal reduction of the axial force in the CFRP strips for $a / h>0.35$. This is probably due to progressive debonding and has an evident effect on the fatigue crack curves (see Fig. 9(a)) for specimens B06 and B07. This phenomenon was not observed in specimen B09, which exhibited a slower fatigue crack growth.

The use of two reinforcement layers results in more pronounced stress bridging in the cracked section and decreases the crack opening displacement. Therefore, the fatigue crack growth rate is reduced and the fatigue life increased. This is clearly proved in Fig. 9, where the results of fatigue tests for two reinforcement layers (specimens B05-B09) are compared to the ones for single reinforcement layer (specimens B03-B04). The fatigue life for two reinforcement layers is, in fact, nine times greater than the one for a single layer.

Comparison of Figs. 11 and 12 shows finally that the tensile force in the CFRP strips for single reinforcement layer is $40 \%$ less than in the two layers case. 
As a result of the above discussion, the fatigue crack growth of cracked steel beams reinforced by using CFRP strips is a quite complex phenomenon governed by the interaction between the fatigue crack growth in the steel plate and the adhesive joint behaviour. This explains the scatter of the experimental results showed in Fig. 9(a).

\section{Conclusions}

Based on the experimental investigations and on the predicted behaviour of the fatigue crack growth in steel beams reinforced using CFRP strips, the following conclusions can be highlighted:

- the fatigue crack growth of damaged steel beams can be effectively reduced by using CFRP reinforcement. Besides, the fatigue behaviour is significantly improved by increasing the number of composite layers. The fatigue life for two reinforcement layers is, in fact, nine times greater than the one for a single layer;

- the crack growth rate is quite large at the beginning of the tests (up to a crack size of approximately $25 \mathrm{~mm}$ ), resulting in a faster fatigue crack propagation. An even faster fatigue crack growth rate was observed for a crack size ranging from about $40 \mathrm{~mm}$ to the final crack size;

- the fatigue crack growth is very sensitive to the tensile force in the CFRP strips. The use of two reinforcement layers increases the tensile force in the reinforcement, resulting in a substantial increment of the fatigue life;

- reinforcement debonding plays an important role in the efficacy of the repair and it lessens the fatigue life;

- finally, the fatigue crack growth in cracked steel sections reinforced by using CFRP strips is a complex phenomenon governed by the adhesive behaviour and by the interaction between the fatigue crack propagation in the steel section and the reinforcement debonding. This leads to a significant scatter of the fatigue crack growth curves in the experimental findings.

\section{Acknowledgements}

The experimental tests were performed at the Material Testing Laboratory of the Politecnico di Milano. The financial support of the Politecnico di Milano is gratefully acknowledged. Thanks are also expressed to Sika Italia S.p.A. for providing the reinforcing materials.

\section{References}

[1] Zhao XL, Zhang L. State of the art review on FRP strengthened steel structures. Engng Struct 2007;29(8):1808-23.

[2] Teng JG, Yu T, Fernando D. Strengthening of steel structures with fiber-reinforced polymer composites. J Constr Steel Res 2012;78:131-43.

[3] Cadei JMC, Stratford TJ, Hollaway LC, Duckett WH. C595 - Strengthening metallic structures using externally bonded fibre-reinforced composites. London: CIRIA; 2004.

[4] Schnerch D, Dawood M, Rizkalla S, Sumner E. Proposed design guidelines for strengthening of steel bridges with FRP materials. Construct Build Mater 2007:21(5):1001-10.

[5] Jiao H, Mashiri F, Zhao XL. A comparative study on fatigue behaviour of steel beams retrofitted with welding, pultruded CFRP plates and wet layup CFRP sheets. Thin-Walled Struct 2012;59:144-52.

[6] Kim YJ, Harries KA. Fatigue behavior of damaged steel beams repaired with CFRP strips. Engng Struct 2011;33(5):1491-502.

[7] Tavakkolizadeh M, Saadatmanesh H. Fatigue strength of steel girders strengthened with carbon fiber reinforced polymer patch. J Struct Engng ASCE 2003;129(1):186-96.

[8] Colombi P, Bassetti A, Nussbaumer A. Crack growth induced delamination on steel members reinforced by prestressed composite patch. Fatigue Fract Engng Mater Struct 2003;26:429-37.

[9] Nussbaumer A, Bassetti A, Colombi P. Elements en Acier Sous Charges de Fatigue Renforces par des Lamelles Precontraintes en Materiau Composite (in French). Construct Metallique 2004;3:3-13.

[10] Nozaka K, Shield CK, Hajjar JF. Effective bond length of carbon-fiber-reinforced polymer strips bonded to fatigue steel bridge I-girders. J Bridge Engng (ASCE) 2005;10(2):195-205.

[11] Deng J, Lee MMK. Fatigue performance of metallic beam strengthened with a bonded CFRP plate. Compos Struct 2007;78:222-31.

[12] Ghafoori E, Motavalli M. Analytical calculation of stress intensity factor of cracked steel I-beams with experimental analysis and 3D digital image correlation measurements. Engng Fract Mech 2011;78:3226-42.

[13] Ghafoori E, Schumacher A, Motavalli M. Fatigue behavior of notched steel beams reinforced with bonded CFRP plates: determination of prestressing level for crack arrest. Engng Struct 2012;45:270-83.

[14] Wu G, Wang H, Wu Z, Liu H, Ren Y. Experimental study on the fatigue behavior of steel beams strengthened with different fiber-reinforced composite plates. J Compos Construct 2012;16(2):127-37.

[15] Colombi P, Fava G. Fatigue life of steel components strengthened with fibre-reinforced polymer (FRP) composites. In: Karbhari VM, editor. Rehabilitation of metallic civil infrastructure using Fiber Reinforced Polymer (FRP) composites. Cambridge (UK): Woodhead; 2014. p. 239-68. 